Omar-Fauzee, M. S., Pringle, A., \& Lavallee, D. (1999). Exercise behavior change and the effect of lost resources. Journal of Personal and Interpersonal Loss, 4, 281

\begin{abstract}
This study was designed to assess to the effects of lost resources on exercise behavior among a sample of 30 foreign exchange students who were identified as having experienced a relapse in their level of physical activity. The first phase of the study was longitudinal in nature, and compared baseline data collected from a sample of 110 exchange students from Malaysia upon their initial arrival in England, with data collected from the same sample four months later. Results of a multivariate analysis of variance indicated a significant effect for scores on processes of change, self-efficacy, and decisional balance $[\underline{F}(12,18)=12.74, \underline{p}<.001]$. Subsequent examination of univariate $\underline{F}$-values also revealed significant differences for self re-evaluation, reinforcement management, self liberation, and self-efficacy. Results from the second phase of the study, which qualitatively assessed the relationship between reductions in physical activity and personal/material resources, revealed that exercise behavior was significantly influenced by resources lost as a result of being in an unfamiliar environment. Implications for health promotion practioners and researchers are discussed.
\end{abstract}




\section{Exercise Behavior Change and the Effect of Lost Resources}

Empirical studies have demonstrated that exercise on a regular basis (i.e., the accumulation of at least 30 minutes of moderate physical activity over the course of most, and ideally all, days of the week; Pate et al., 1995) can assist in the prevention and treatment of numerous clinical conditions and diseases, including osteoporosis, adult-onset diabetes, hypertension, and coronary heart disease (e.g., American College of Sports Medicine, 1995; Blair, Kohl, Gordon, \& Paffenbarger, 1992). Researchers have also suggested that exercise can enhance mental health and well-being, both in the short- and long-term (e.g., Martinsen, Hoffart, \& Solberg, 1989; McEntee \& Halgin, 1996). However, a lack of adherence to regular exercise continues to be documented, with an approximately attrition rate of $50 \%$ among those individuals who commence exercise programs (Dishman \& Buckworth, 1998). Therefore, one of the principle challenges currently facing exercise psychologists is to determine ways to help the overall population adopt, and then maintain, participation in habitual exercise-related activity (Gorely \& Gordon, 1995; Wankell, Yardley, \& Graham, 1985).

The transtheoretical model has been employed as an integrative and comprehensive model of exercise behavior change (Prochaska et al., 1994). This model was primarily developed as a framework to describe the different phases involved in the acquisition or cessation of a particular behavior (Marcus, Selby, Niaura, \& Rossi, 1992), and has since been applied to the maintenance of several health-related behaviors, including exercise (e.g., Gorely \& Gordon, 1995; Marcus \& Simkin, 1993; Nigg \& Courneya, 1998). The model is considered transtheoretical because it encompasses features of the stages of change model (Prochaska \& DiClemente, 1983), self-efficacy theory (Bandura, 1986), processes of change model (Prochaska, DiClemente, \& Norcross, 1992), and decisional balance theory (Janis \& Mann, 1977).

As outlined by Prochaska and DiClemente (1983), the stages of change model (as it applies to exercise behavior) represents a framework of five stages that individuals progress 
through, including: (1) precontemplation (i.e., individuals who do not engage in exerciserelated behavior and do not intend to start in the near future); (2) contemplation (i.e., individuals who do not engage in exercise-related behavior, but have an intention to start in the near future); (3) preparation (i.e., individuals who engage in some exercise-related behavior, but not on a regular basis); (4) action (i.e., individuals who are currently engaging in exercise-related behavior, but have only recently started); and (5) maintenance (i.e., individuals who are currently engaging in exercise-related behavior, and have been doing so for some time). It is hypothesized that as individuals change from an unhealthy to a healthy behavior, they will progress through these stages in a cyclical fashion, with both periods of progression and regression (Gorley \& Gordon, 1995; Prochaska \& Marcus, 1994).

Self-efficacy is a judgement regarding one's capability to organize and execute courses of action required to attain designated types of performance, and is believed to influence choice, effort expenditure, thought patterns, emotional reactions, and behavioral performance (Bandura, 1986). Processes of change are overt or covert activities that individuals use to modify their experiences and/or environment in order to change their behavior(s), and include consciousness raising, dramatic relief, environmental re-evaluation, self re-evaluation, social liberation, counter conditioning, helping relationships, reinforcement management, self liberation, and stimulus control (Prochaska et al., 1992). Decisional balance is a process which incorporates self-behavior, self-esteem, and social approval, and consists of the benefits (i.e., decision balance [pro]) and costs (i.e., decision balance [con]) of behavior to both the self and others (Janis \& Mann, 1977). Studies have demonstrated that self-efficacy, the use of the processes of change, and decisional balance are employed uniquely at each stage of change throughout the behavior change process (e.g., Gorley \& Gordon, 1995; Marcus \& Owen, 1992; Prochaska et al., 1994).

In order to investigate the effect of lost resources (both personal and material) on exerciserelated behavior, we designed a study to examine the stages of change, self-efficacy, processes of change, and decisional balance among a sample of foreign exchange students. 
The first phase of this study was longitudinal in nature, and consisted of comparing levels of the variables of interest among a sample of exchange students from Malaysia (upon their initial arrival in England) with data collected with the same sample four months later. Research on the psychology of unfamiliar environments has suggested that foreign exchange students often lose a substantial amount of resources when studying abroad (Furnham \& Bochner, 1999). Moreover, the application of the transtheoretical model during different developmental periods is required in order to develop, as well as match, interventions for specific populations (Calfas, Sallis, Lovato, \& Campbell, 1994; Marcus, 1995).

The issue of relapse is also an important challenge in health behavior (Gorley \& Gordon, 1995; Marcus, Simkin, Rossi, \& Pinto, 1996), as researchers have been able to identify only a few factors that may contribute to this phenomenon (e.g., Brownell, Marlatt, Lichtenstein, \& Wilson, 1986; King \& Fredrikson, 1984). Thus, a further purpose of this study was to assess the transtheoretical model among a sample who had experienced a relapse in exercise behavior. A relapser has been referred to in the exercise science literature by Marcus et al. (1996) as an individual who moves in a regressive pattern from the preparation, action, or maintenance stage back to either the precontemplation or contemplation stage. Due to the exploratory nature of this study, however, we defined a relapser as an individual who moves in any regressive pattern by at least one stage (e.g., from action to preparation).

\section{Method}

\section{$\underline{\text { Participants }}$}

Thirty students at two large universities in England, who had temporarily relocated from Malaysia for the purpose of studying abroad for at least one year, participated in this study. In order to identity a sample who had experienced a relapse in exercise-related behavior, 170 students were initially invited to complete a battery of questionnaires upon their arrival in England, and prior to the commencement of their academic studies. This battery consisted of validated questionnaires utilized in previously published research in the area of exercise behavior change, and included the Stages of Change Instrument (Marcus \& Simkin, 1993), 
Processes of Change Questionnaire (Marcus, Rossi, Selby, Niaura, \& Abrams, 1992), SelfEfficacy Questionnaire (Marcus, Selby, et al., 1992), and Decision-Balance Questionnaire (Marcus \& Owen, 1992).

Questionnaires were completed by 110 participants (return rate $=64.7 \%$ ), and by employing Marcus and Simkin’s (1993) Stages of Change Instrument, 19 (17.3\%) individuals were classified in the precontemplation stage, 23 (20.9\%) in the contemplation stage, 49 (44.5\%) in the preparation stage, $11(10.0 \%)$ in the action stage, and eight (7.3\%) in the maintenance stage. A follow-up data collection (with the same battery of questionnaires) with the respondents subsequently occurred four months after baseline measures were obtained. A total of 90 questionnaires were returned during this data collection (return rate $=$ 81.8\%), and following a comparison with baseline data, 30 participants (27.3\%) were classified as relapsers (i.e., individuals who moved in a regressive pattern by at least one stage).

\section{$\underline{\text { Procedure }}$}

Data was collected by inviting each participant, who was classified as a relapser, to write a narrative account describing their exercise behavior change (Gergen \& Gergen, 1988). More specifically, relapsers were asked to focus on how resources lost as a result of being a foreign exchange student may have had an impact on their reduction in exercise-related behavior (since their arrival in England). Dichotomous coding was employed by having two judges (viz., two PhD students specializing in exercise psychology) independently assess whether predetermined factors were present or absent from each of the narratives (cf., Baumeister, Stillwell, \& Wotman, 1992). The predetermined factors were developed from the results of an earlier study with a separate sample of foreign exchange students from Malaysia, and included changes in weather condition, lack of time, lack of an exercise partner, attituderelated factors, health-related factors, loss of interest, lack of childcare facilities, lack of experience, and lack of guidance (Omar-Fauzee, Lavallee, Nesti, \& Mahoney, 1998). The extent to which each of these factors was related to exercise behavior change was rated on a 
10-point scale (with higher scores representing higher levels of the particular factor), and the average score from the two judges was used in subsequent analyses.

\section{Results}

The relapse sample had an overall mean age of 27.13 years $(\mathrm{SD}=7.83)$, and consisted of 12 females and 18 males, and 16 undergraduate students and 14 graduate students. Chisquare results showed that the relationship between the stages of change and demographic variables (i.e., gender, age, and level of study) among this sample were not significantly different. Multivariate analysis of variance indicated a significant difference between baseline and follow-up scores for processes of change, self-efficacy, and decisional balance $[\underline{F}(12,18)=12.74, \underline{p}<.001]$. As outlined in Table 1 , subsequent examination of univariate F-values revealed significant differences for the following variables: self re-evaluation; reinforcement management; self liberation; and self-efficacy.

Of the 30 individuals who were invited to participate in the narrative data collection, 19 (6 females; 13 males) responded (return rate $=63 \%$ ). An inter-rater agreement of .81 was obtained between the two coders, with the following mean and standard deviation scores for the predetermined factors which influenced exercise-related behavior: change in weather conditions $(\underline{\mathrm{M}}=9.56$; $\underline{\mathrm{SD}}=.38)$; lack of time $(\underline{\mathrm{M}}=7.84$; $\underline{\mathrm{SD}}=2.41)$; lack of an exercise partner $(\underline{\mathrm{M}}=7.63$; $\underline{\mathrm{SD}}=1.97)$; attitude-related factors $(\underline{\mathrm{M}}=7.39$; $\underline{\mathrm{SD}}=2.55)$; health-related factors $(\underline{\mathrm{M}}=6.56$; $\underline{\mathrm{SD}}=2.82)$; loss of interest $(\underline{\mathrm{M}}=6.54$; $\underline{\mathrm{SD}}=2.51)$; lack of childcare facilities $(\underline{\mathrm{M}}=6.10 ; \underline{\mathrm{SD}}=3.11)$; lack of experience $(\underline{\mathrm{M}}=3.07$; $\underline{\mathrm{SD}}=2.54)$; and lack of guidance $(\underline{\mathrm{M}}=2.88 ; \underline{\mathrm{SD}}=3.09)$.

\section{Discussion}

The preliminary findings based on the Stages of Change Instrument (Marcus \& Simkin, 1993) determined that nearly two thirds of the overall sample (i.e., 110 foreign exchange students) resided two stages or less from entering into the action stage of exercise behavior. The fact that such a high number of individuals were in these particular stages (viz., precontemplation, contemplation, and preparation) may be explained in part by Furnham and 
Bochner's (1999) suggestion that relocation to a new environment provides unique changes and challenges, and that this often leads participation in formal exercise programs to become a secondary priority.

Results of our analyses with the sample of individuals who relapsed by at least one stage also revealed that exercise behavior was significantly influenced by resources lost as a result of being in an unfamiliar environment. These resources were found to be both material and personal in nature (e.g., exercise facilities, organized physical activity provision, access to transport), and exercise psychology researchers have suggested that such resources are vital in surmounting barriers which threaten exercise adherence (e.g., Marcus et al., 1996). In particular, social support has been identified as a coping resource which can help improve exercise adherence and increase exercise frequency (Gottlieb, 1993; King \& Fredriksen, 1984; Wankell et al., 1985). In this study, the relapse sample specifically highlighted the lack of an exercise partner as a significant reason for their change in exercise behavior.

Consequently, the loss of support networks upon relocation could partly explain attrition from participation in formal exercise programmes. As Gottlieb (1993) has suggested, the decision to participate in physical activity poses a complex process of cognitive appraisal of individual goals, perceived costs and benefits, and coping resources. Therefore, the importance of having a network to help support the individual in commencing exercise behavior, as well as assist in managing the demands associated with the adoption of a physically active lifestyle, should not be underestimated.

It has been argued that in view of the barriers faced prior to, and during, the adoption of an exercise programme, individuals need to be prepared to the point where they are able to cope with the demands that such a behavior change poses (Gorely \& Gordon, 1995; Marcus, Selby, et al., 1992; Prochaska et al., 1994). As identified in this study, however, there are often deficiencies in the manner in which different populations are catered for in terms of their preparation for a physically-active lifestyle. Researchers have highlighted that physical activity interventions have traditionally been designed for individuals who are ready to make 
a change towards the adoption of an exercise programme, rather than preparing them for such changes that exercise adoption poses (e.g., Dishman \& Buckworth, 1998; Marcus, Rossi, et al., 1992; Prochaska \& Marcus, 1994). When consideration is given to the sample in this study who experienced a relapse, however, there is an important case for designing interventions which consider the stage of behavior change that individuals are in (i.e., precontemplation, etc.) and cater for their needs in respect of the stage (Marcus, 1995).

For practitioners working in this area, issues for consideration within such staged-matched interventions include problem identification (i.e., what the reasons are which influenced a relapse in exercise behavior), identification of the best way(s) to surmount the problem, and development of an action plan to assist individuals in adopting exercise behavior (Marcus, 1995). Given the results of this study, heath promotion professionals may also want to address self-efficacy and specific processes of change (e.g., self re-evaluation, reinforcement management, and self-liberation) within the context of a preparatory intervention geared at encouraging the adoption of a physically active lifestyle.

Prochaska and Marcus (1994) have also suggested that there is the danger that practitioners mistake a lack of interest as a loss of motivation in making a behavior change, and thus, run the risk of alienating such groups further. Indeed, a lack of interest has been found to be one of the predominant reasons why foreign exchange students decrease their physical activity levels (Omar-Fauzee et al., 1998). What is necessary, however, is for practitioners to understand the reasons for exercise behavior and identify what these are in relation to the issues associated with them. We believe that this may help in a better understanding of the processes which people experience when making exercise behavior changes. It is equally important that practitioners also consider the issue of sustainability to stage-matched interventions, both in their delivery and during follow-up, as there is a need to avoid an over-reliance by people on the mechanisms that are intended to prepare them for an independent exercise lifestyle. As Marcus (1995) has suggested, long-term maintenance of 
physical activity is rarely re-assessed, and the question whether exercise behavior is maintained following the conclusion of an intervention remains unanswered.

Although empirical evidence is accumulating in the area of exercise behavior change with populations from countries such as Australia, Canada, England, and the United States, data is lacking among individuals from developing countries (Marcus \& Simkin, 1993). Moreover, it has been reported that minority groups and other underserved populations are at-risk of being inactive segments of the overall population (Omar-Fauzee et al., 1998; Marcus, 1995). Therefore, we would suggest that future research be undertaken which further examines exercise behavior change among minority populations. There is also a need to further consider higher education settings as a resource to help promote exercise behavior (Calfas et al., 1994), as this environment is rich in facility provision, organized physical activity programs, and organizations with a skill base to promote exercise. 


\section{References}

American College of Sports Medicine (1995). Osteoporosis and exercise. Medicine and Science in Sports and Exercise, 27 (4), i-vii.

Bandura, A. (1986). Social foundations of though and action. Englewood Cliffs, NJ: Prentice.

Baumeister, R. F., Stillwell, A., \& Wotman, S. R. (1990). Victim and perpetrator accounts of interpersonal conflict: Autobiographical narratives about anger. Journal of Personality and Social Psychology, 59, 994-1005.

Blair, S. N., Kohl, H. W., Gordon, N. F., \& Paffenbarger, R. S. (1992). How much physical activity is good for health? Annual Review of Public Health, 13, 99-126.

Brownell, K. D., Marlatt, G. A., Lichenstein, E., \& Wilson, G. T. (1986). Understanding and preventing relapse. American Psychologist, 41, 765-782.

Calfas, K. J., Sallis, J. F., Lovato, C. Y., \& Campbell, J. (1994). Physical activity and its determinants before and after college graduation. Medicine, Exercise, Nutrition and Health, $\underline{3,323-334 .}$

Dishman, R. K., \& Buckworth, J. (1998). Exercise psychology. In J. M. Williams (Ed.), Applied sport psychology: Personal growth to peak performance (pp. 454-464). Mountain View, CA: Mayfield.

Furnham, A., \& Bochner, S. (1999). Culture shock: Psychological reactions to unfamiliar environments. London: Methuen.

Gergen, K. L., \& Gergen, M. M. (1988). Narrative and the self as relationship. Advances in Experimental Social Psychology, 21, 17-56.

Gorely, T., \& Gordon, S. (1995). An examination of the transtheoretical model and exercise behavior in older adults. Journal of Sport \& Exercise Psychology, 17, 312-324.

Gottlieb, B. H. (1993). The meaning and importance of social support. In H. A. Quinney, L. Gauvin, \& A. E. Wall (Eds.), Toward active living: Proceedings of an international 
conference on physical activity, fitness and health (pp. 227-232). Champaign, IL: Human Kinetics.

Janis, I. L., \& Mann, L. (1977). Decision making: A psychological analysis of conflict, choice, and commitments. London: Metheun.

King, A. C., \& Fredriksen, L. W. (1984). Low cost strategies for increasing exercise behavior: Relapse preparation, training, and social support. Behavior Modification, 8, 3-21.

Marcus, B. H. (1995) Exercise behavior and strategies for intervention. Research Quarterly for Exercise and Sport, 66, 319-323.

Marcus, B. H., \& Owen, N. (1992). Motivational readiness, self-efficacy and decisionmaking for exercise. Journal of Applied Psychology, 22, 3-16.

Marcus, B. H., Rossi, J. S., Selby, V. C., Niaura, R. S., \& Abrams, D. B. (1992). The stages and processes of exercise adoption and maintenance in a worksite sample. $\underline{\text { Health }}$ Psychology, 11, 386-395.

Marcus, B. H., Selby, V. C., Niaura, R. S., \& Rossi, J. S. (1992). Self-efficacy and the stages of exercise behavior change. Research Quarterly for Exercise and Sport, 63, 60-66.

Marcus, B. H., \& Simkin, L. R. (1993). The stages of exercise behavior. The Journal of Sport Medicine and Physical Fitness, 33, 83-88.

Marcus, B. H., Simkin, L. R., Rossi, J. S., \& Pinto, B. M. (1996). Longitudinal shifts in employees' stages and processes of exercise behavior change. American Journal of Health Promotion, 10, 195-200.

Martinsen, E. W., Hoffart, A., \& Solberg, O. (1989). Comparing aerobic with nonaerobic forms of exercise in the treatment of clinical depression: A randomized trail. Comprehensive Psychiatry, 30, 324-331.

McEntee, D. J., \& Halgin, R. P. (1996). Therapists’ attitudes about addressing the role of exercise in psychotherapy. Journal of Clinical Psychology, 52, 48-60.

Nigg, C. R., \& Courneya, K. S. (1998). Transtheoretical model: Examining adolescent behavior. Journal of Adolescent Health, 22, 214-224. 
Omar-Fauzee, M. S., Lavallee, D., Nesti, M., \& Mahoney, C. A. (September, 1998).

Psychological factors influencing exercise behaviour change among students in an unfamiliar environment. Poster presented at the Annual Conference of the Social Psychology Section of the British Psychological Society, Kent.

Pate, R. R., Pratt, M., Blair, S. N., Haskell, W. L., Macera, C. A., Bouchard, C., Buchner, D., Caspersen, C. J., Ettinger, W., Health, G. W., King, A. C., Kriska, A., Leon, A. S., Marcus, B. H., Morris, J., Paffenbarger, R. S., Patrick, K., Pollock, M. L., Rippe, J. M., Sallis, J., \& Wilmore, J. H. (1995). Physical activity and public health: A recommendation from the Centers for Disease Control and Prevention and the American College of Sports Medicine. Journal of the American Medical Association, 273, 402-407.

Prochaska, J. O., \& DiClemente, C. C. (1983). Stages and processes of self-change of smoking: Toward an integrative model of change. Journal of Consulting and Clinical Psychology, 51, 390-395.

Prochaska, J. O., DiClemente, C. C., \& Norcross, J. C. (1992). In search of how people change: Applications to addictive behaviors. American Psychologist, 47, 1102-1114.

Prochaska, J. O., \& Marcus, B. H. (1994). The transtheoretical model: Applications to exercise. In R. K. Dishman (Ed.), Advances in exercise adherence (pp. 161-185).

Champaign, IL: Human Kinetics.

Prochaska, J. O., Velicer, W. F., Rossi, J. S., Goldstein, M. G., Marcus, B. H., Rakowski, W., Fiore, C., Harlow, L. L., Redding, C. A., Rosenbloom, D., \& Rossi, S. R. (1994). Stages of change and decisional balance for 12 problem behaviors. Health Psychologist, 13, 39-46.

Wankell, L. M., Yardley J. K., \& Graham, J. (1985). The effects of motivational interventions upon exercise adherence of high and low self motivated adults. Canadian Journal of Personality and Social Psychology, 55, 128-141. 
Table 1

Means, Standard Deviations, and F-Values for Processes of Change, Self-Efficacy, and $\underline{\text { Decisional Balance }}$

\begin{tabular}{|c|c|c|c|c|c|}
\hline \multirow[b]{2}{*}{ Variable } & \multicolumn{2}{|c|}{ Baseline } & \multicolumn{2}{|c|}{ Follow-up } & \multirow[b]{2}{*}{$\underline{F}$-value } \\
\hline & Mean & SD & Mean & SD & \\
\hline Consciousness raising $^{a}$ & 10.67 & 2.43 & 10.50 & 3.54 & 0.10 \\
\hline Environmental re-evaluation ${ }^{a}$ & 9.63 & 3.03 & 9.23 & 3.53 & 0.48 \\
\hline Self re-evaluation ${ }^{\text {a }}$ & 13.70 & 3.27 & 12.10 & 3.56 & $20.03 * * *$ \\
\hline Social liberation ${ }^{\mathrm{a}}$ & 9.87 & 2.75 & 8.93 & 2.46 & 3.68 \\
\hline Counter conditioning $^{\mathrm{a}}$ & 12.03 & 3.29 & 11.17 & 3.18 & 3.21 \\
\hline Helping relationships ${ }^{a}$ & 7.57 & 3.20 & 6.93 & 3.06 & 1.07 \\
\hline Reinforcement management ${ }^{a}$ & 13.37 & 2.87 & 11.99 & 3.46 & $10.32 * *$ \\
\hline Self liberation ${ }^{a}$ & 14.23 & 2.98 & 12.80 & 3.59 & $9.85^{* *}$ \\
\hline Stimulus control $^{\mathrm{a}}$ & 9.80 & 2.93 & 9.07 & 3.17 & 4.18 \\
\hline Dramatic relief $^{\mathrm{b}}$ & 7.97 & 2.63 & 7.57 & 2.66 & 0.72 \\
\hline Decision balance (pro) $^{\mathrm{b}}$ & 10.33 & 2.06 & 9.80 & 2.29 & 1.99 \\
\hline Decision balance (con) ${ }^{\mathrm{b}}$ & 5.87 & 2.11 & 6.27 & 1.86 & 1.17 \\
\hline Self-efficacy ${ }^{c}$ & 12.33 & 5.93 & 10.13 & 6.17 & $7.15^{*}$ \\
\hline
\end{tabular}

Note. $\underline{N}=30$

${ }^{\mathrm{a}}$ Range $=4-20 .{ }^{\mathrm{b}}$ Range $=3-15 .{ }^{\mathrm{c}}$ Range $=0-35$

${ }^{*} \mathrm{p}<.05 .^{* *} \mathrm{p}<.01 .^{* * *} \mathrm{p}<.001$. 